\title{
“Casa: lar, doce lar ou prisão domiciliar?" uma perspectiva fenomenológica segundo codependentes de usuários de substâncias psicoativas
}

\author{
"Home: home, sweet home or house prison?" a phenomenological perspective according to \\ codependents of users of psychoactive substances \\ "Hogar: hogar, dulce hogar o casa prisión?" una perspectiva fenomenológica según los \\ codependientes de usuarios de sustancias psicoactivas
}

Recebido: 29/12/2020 | Revisado: 30/12/2020 | Aceito: 02/01/2021 | Publicado: 04/01/2021

Leone Mendes Dias

ORCID: https://orcid.org/0000-0002-9623-819X

Universidade Federal de Juiz de Fora, Brasil E-mail: leone.mendes@hotmail.com

Marcelo da Silva Alves

ORCID: https://orcid.org/0000-0003-0311-1673

Universidade Federal de Juiz de Fora, Brasil

E-mail: enfermarjf@gmail.com

Maria Odete Pereira

ORCID: https://orcid.org/0000-0002-9418-2524

Universidade Federal de Minas Gerais, Brasil

E-mail: m.odetepereira@gmail.com

Cristina Arreguy-Sena

ORCID: https://orcid.org/0000-0002-5928-0495

Universidade Federal de Juiz de Fora, Brasil E-mail: cristina.arreguy@ufjf.edu.br

Laércio Deleon de Melo

ORCID: https://orcid.org/0000-0002-8470-7040

Universidade do Estado do Rio de Janeiro, Brasil E-mail: laerciod128@hotmail.com

Camila Cristina Gregório de Assis ORCID: https://orcid.org/0000-0002-8590-9613

Universidade Federal de Juiz de Fora, Brasil E-mail: camilacgassis@gmail.com

Thelma Spindola

ORCID: https://orcid.org/0000-0002-1785-5828 Universidade do Estado do Rio de Janeiro, Brasil E-mail: tspindola.uerj@gmail.com

Felipe Eduardo Taroco

ORCID: https://orcid.org/0000-0002-8530-5780

Centro Universitário Estácio de Juiz de Fora, Brasil E-mail: fisiofelipe91@gmail.com

\begin{abstract}
Resumo
Objetivou-se refletir sobre o ambiente domiciliar de codependentes como um ambiente de convivência com adictos de substâncias psicoativas numa perspectiva fenomenológica. Investigação descritiva, delineada na abordagem fenomenológica à luz do referencial teórico-metodológico-filosófico de Michel Maffesoli, realizada numa Unidade Básica de Saúde em Minas Gerais, Brasil, com oito codependentes. Coletaram-se dados de caracterização e foram realizadas entrevistas individuais em profundidade gravadas. Trataram-se os dados com análise de conteúdo fenomenológico com apoio dos softwares SPSS versão 24 e NVivo Proll. Atenderam-se todos os aspectos éticolegais de pesquisa. Os oito sujeitos eram mulheres. Compreendeu-se que o "lar" pode se tornar uma verdadeira "Prisão domiciliar" quando a realidade cotidiana for marcada pelos múltiplos papéis ocupados pelas participantes, os quais são gerenciados juntamente com o cuidado ao familiar dependente químico. Portanto, as situações estressoras, dolorosas, que geram sentimentos ruins, como medo, insegurança, tristeza, e os conflitos familiares devem ser alvo do cuidado de enfermagem.

Palavras-chave: Codependência psicológica; Relações familiares; Transtornos relacionados ao uso de substâncias; Atenção primária à saúde.
\end{abstract}




\begin{abstract}
The objective was to reflect on the home environment of codependents as an environment of coexistence with addicts of psychoactive substances in a phenomenological perspective. Descriptive investigation, outlined in the phenomenological approach in the light of Michel Maffesoli's theoretical-methodological-philosophical framework, carried out in a Basic Health Unit in Minas Gerais, Brazil, with 08 codependents. Characterization data were collected and recorded individual in-depth interviews were conducted. Data treatment with phenomenological content analysis supported by SPSS software version 24 and NVivo Pro11. All ethical and legal aspects of research were met. The eight participants were $100 \%$ women. It was understood that this "home" can become a real "house arrest" when the everyday reality is marked by the multiple roles occupied by the participants who are managed together with the care of the chemical dependent family member. Stressful, painful situations that generate bad feelings such as fear, insecurity, sadness, and family conflicts must be the target of nursing care.
\end{abstract}

Keywords: Codependency psychological; Family relations; Substance-related disorders; Primary health care.

\title{
Resumen
}

El objetivo fue reflexionar sobre el entorno familiar de los codependientes como entorno de convivencia con adictos a sustancias psicoactivas desde una perspectiva fenomenológica. Investigación descriptiva, planteada en el enfoque fenomenológico a la luz del marco teórico-metodológico-filosófico de Michel Maffesoli, realizada en una Unidad Básica de Salud en Minas Gerais, Brasil, con ocho codependientes. Se recopilaron datos de caracterización y se grabaron entrevistas individuales en profundidad. Los datos fueron tratados con análisis de contenido fenomenológico con el apoyo del software SPSS versión 24 y NVivo Pro11. Se cumplieron todos los aspectos éticos y legales de la investigación. Los ocho sujetos eran mujeres. Se entendió que el "hogar" puede convertirse en un verdadero "arresto domiciliario" cuando la realidad cotidiana está marcada por los múltiples roles que ocupan los participantes, que se manejan junto con el cuidado del familiar dependiente de sustancias químicas. Por tanto, las situaciones estresantes, dolorosas que generan malos sentimientos, como el miedo, la inseguridad, la tristeza y los conflictos familiares, deben ser el objetivo de los cuidados de enfermería.

Palabras clave: Codependencia psicológica; Relaciones familiares; Transtornos relacionados com substancias; Atención primaria de salud.

\section{Introdução}

A convivência familiar com pessoas que possuem algum tipo de dependência química, por exemplo, de drogas lícitas, como bebidas alcoólicas e tabaco, ou de drogas ilícitas, como a maconha, o crack, a heroína, entre outras (Brasil, 2019), envolve as dimensões física, psíquica e comportamental (Melo et al., 2020) e pode resultar em prejuízos biopsicossociais aos membros da família, em curto, médio ou longo prazo, especialmente àqueles que são responsáveis pelo cuidado ao dependente de alguma Substância Psicoativa (SPA). Estes sofrem consequências como a codependência, que é considerada um transtorno emocional que acontece em indivíduos que mantêm uma convivência diária com usuários de SPA (Meira et al., 2020).

Nas relações cotidianas, na maioria das vezes, os codependentes se mostram como suficientes, equilibrados, corajosos, dominadores, quando, na verdade, sentem-se impotentes, amedrontados, dominados pelo vício do outro. É uma relação que acontece inconscientemente e, quando o codependente cai em si, ele já deixou de viver sua própria vida e passou a viver em função do dependente e até mesmo a sua relação com o ambiente domiciliar e a satisfação com o seu lar podem estar comprometidas (Alvarez, Gomes \& Xavier, 2014).

Diante do exposto, identificou-se uma lacuna científica no que tange a reflexões numa perspectiva fenomenológica sobre o modo como os codependentes de SPAs se sentem em seus lares como ambiente de convivência e compartilhamento de cuidados para com o familiar dependente químico, numa realidade da Atenção Básica (AB).

Justifica-se, portanto, a relevância desta investigação devido à possibilidade de contribuir com novos conhecimentos para o campo da enfermagem e da saúde como um todo por meio das reflexões apresentadas. Objetivou-se, assim, refletir sob uma perspectiva fenomenológica acerca do ambiente domiciliar de codependentes como um ambiente de convivência com adictos de substâncias psicoativas. 


\section{Metodologia}

Foi realizada uma investigação descritiva, delineada na abordagem fenomenológica à luz do referencial teóricometodológico-filosófico de Michel Maffesoli. A abordagem adotada permite aos pesquisadores compreender os fenômenos por meio de uma lógica existencialista, que leva em consideração não apenas o momento, mas toda a história do cotidiano que é desvelado a todo instante. É possível ainda um aprimoramento do modo de ver e viver do pesquisador, orientando-o para uma expertise a respeito de fenômenos corriqueiros, nunca vistos em sua totalidade em relação a sua essência e singularidade (Maffesoli, 2010; Nistchke et al., 2017). Foram atendidos os critérios do COnsolidated criteria for REporting Qualitative Research (COREQ).

O cenário de investigação viabilizado foi uma Unidade Básica de Saúde (UBS) da Zona da Mata Mineira, Brasil, pertencente a uma região sanitária de saúde coberta pela Estratégia Saúde da Família (ESF) do Sistema Único de Saúde (SUS). A população estimada da área é de 6.612 pessoas, com elevados índices de violência associada ao narcotráfico e vulnerabilidades sociais e econômicas (Brasil, 2020).

Os potenciais participantes foram recrutados pelo pesquisador principal por meio de convite individual em domicílio. A amostragem por conveniência se dei por cadastro prévio de 20 dependentes de SPAs pertencentes à área de abrangência da UBS investigada. Foram critérios de inclusão: ser familiar de dependente de SPAs e ter idade $\geq 18$ anos. Foram excluídos aqueles que não eram o cuidador principal da pessoa dependente de SPA, não residiam com o dependente, externaram desejo de interromper sua participação ou adiaram o agendamento de coleta por $\geq$ três abordagens. Foram, portanto, 12 perdas justificadas por recusa desses familiares codependentes, tendo sido incluídos na investigação oito $(\mathrm{N}=8)$ participantes.

O instrumento de coleta foi estruturado em: 1) caracterização sociodemográfica; 2) entrevista individual em profundidade com gravação de áudio; 3) diário de campo contendo observações e conteúdos relevantes ao pesquisador. Os registros foram feitos imediatamente após o término da entrevista individualizada no processo de coleta de dados.

A coleta de fados foi realizada por um dos pesquisadores, mestrando em enfermagem, previamente treinado, que construiu vínculos anteriores com os potenciais participantes, motivado por sua inserção em visitas domiciliares realizadas juntamente com os profissionais da UBS, sendo reconhecido pelos possíveis participantes como integrante da equipe. Isso favoreceu a abordagem requerida pela entrevista individual em profundidade fenomenológica.

Foram questões norteadoras elaboradas previamente pelos pesquisadores com base no referencial teóricometodológico-filosófico adotado e objeto de investigação: como é, para você, o cotidiano na convivência com um familiar dependente químico e os cuidados direcionados a ele? Mediante essa problemática envolvendo o seu familiar dependente, como você avalia o seu lar, como ele é influenciado e como você se sente dentro de sua casa? Conte-me algum fato vivenciado envolvendo você ou alguém com quem você se relaciona sobre as dificuldades encontradas no cotidiano de residir com e cuidar de um usuário dependente químico.

As entrevistas individuais em profundidade, em abordagem única, com gravação de áudio (duração de \pm 60 minutos), ocorreram no período de fevereiro a julho de 2018, sendo a durabilidade de seis meses de coleta justificada pelas dificuldades de agendamento por parte dos Agentes Comunitários de Saúde (ACSs). Utilizou-se o software Open Data Kit (ODK) 2.0 para o registro das variáveis de caracterização e dos conteúdos do diário de campo. Essa estratégia reduziu vieses de transcrição de dados ou omissão de informações no processo de transcrição.

Os dados de caracterização foram tratados em software Statistical Package for the Social Sciences (SPSS), versão 24, analisados com estatística descritiva (tendência central e dispersão). Os conteúdos das entrevistas foram consolidados e analisados através das unidades de análises sistematizadas em uma perspectiva compreensiva do cotidiano.

Para a captação do fenômeno investigado, na perspectiva individual, seguiram-se as fases de "descrição", "intuição" e "metáfora", sendo a primeira envolvida na etapa de coleta dos dados e as duas últimas na fase de análise dos dados. Isso para 
que a abordagem fenomenológica ocorresse com consistência teórica, visando à compreensão do ser humano em sua integralidade existencial complexa na visão individual, peculiar e subjetiva dos participantes, evitando-se vieses ou suposições dos pesquisadores (Maffesoli, 2010; Nitschke et al., 2017).

A análise dos conteúdos gravados, após sua transcrição na íntegra, foi realizada de modo a favorecer uma aproximação, assimilação e compreensão do cotidiano do codependente ao conviver com um familiar dependente de SPAs e suas relações com os profissionais de saúde no contexto da APS. O tratamento dos discursos dos participantes ocorreu com o apoio do software NVivo Pro $11^{\circledR}$, com o estabelecimento das categorias de análise (unidades de registro e de análise) com base nos codificadores e na definição dos temas emergidos dos dados.

O adensamento teórico foi confirmado mediante repetição e frequência dos conteúdos, além da observância da ausência de novas informações complementares ao objetivo da presente investigação, constatando-se assim a saturação teórica dos resultados. Essa confirmação foi observada ainda pela capacidade dos dados em refletir, em quantidade e intensidade, as múltiplas dimensões do fenômeno investigado, garantindo-se a qualidade e a integração dos resultados (Minayo, 2017).

Foram atendidos todos os aspectos éticos e legais de pesquisas envolvendo seres humanos. Este estudo integrou uma investigação matriz intitulada "O Cotidiano de Familiares de Indivíduos com Dependência Química no Contexto da Atenção Primária à Saúde" aprovada pelo Comitê de Ética em Pesquisa (CEP) sob Parecer Consubstanciado n 2.478.973, de 30/01/18. A aquiescência dos participantes foi externada pela assinatura do Termo de Consentimento Livre e Esclarecido (TCLE) pósesclarecimento de objetivos, finalidades da pesquisa e potenciais riscos/benefícios de sua participação. O anonimato foi garantido mediante o estabelecimento de codinomes (ex: Bebel).

\section{Resultados e Discussão}

A caracterização das participantes codependentes de SPAs ficou assim definida: eram oito mulheres (100\%), que tinham idade média de 56 anos (variabilidade de 33 a 72 anos). O perfil sociodemográfico e profissional foi apresentado na Tabela 1. Cabe mencionar que, no que tange a escolaridade, profissão, situação conjugal e religião, o resultado encontrado foi similar ao achado de outras investigações realizadas no contexto da AB (Arreguy-Sena et al., 2020; Melo et al., 2020). 
Tabela 1. Caracterização sociodemográfica e profissional das oito participantes. Juiz de Fora, Minas Gerais, Brasil, 2020.

\begin{tabular}{|c|c|c|c|}
\hline Perfil sociodemográfico, profissional e econômico & & $F$ & $\%$ \\
\hline \multicolumn{4}{|l|}{ Cor de pele autodeclarada } \\
\hline Branca & & 4 & 50 \\
\hline Negra & & 4 & 50 \\
\hline & Total & 40 & 100 \\
\hline \multicolumn{4}{|l|}{ Situação conjugal } \\
\hline Casadas & & 5 & 62,5 \\
\hline Viúvas & & 2 & 25 \\
\hline Solteiras & & 1 & 12,5 \\
\hline & Total & 8 & 100 \\
\hline \multicolumn{4}{|l|}{ Religião } \\
\hline Católica & & 6 & 75 \\
\hline Evangélica & & 1 & 12,5 \\
\hline Espírita & & 1 & 12,5 \\
\hline & Total & 8 & 100 \\
\hline \multicolumn{4}{|l|}{ Escolaridade } \\
\hline Ensino fundamental & & 4 & 50 \\
\hline Ensino médio & & 2 & 25 \\
\hline Ensino superior & & 2 & 25 \\
\hline & Total & 8 & 100 \\
\hline \multicolumn{4}{|l|}{ Profissão } \\
\hline Comerciantes & & 1 & 12,5 \\
\hline Serviços domésticos & & 7 & 87,5 \\
\hline & Total & 8 & 100 \\
\hline \multicolumn{4}{|l|}{ Aposentadoria } \\
\hline Sim & & 2 & 25 \\
\hline Não & & 6 & 75 \\
\hline & Total & 8 & 100 \\
\hline \multicolumn{4}{|l|}{ Grau de Parentesco com o dependente de SPA } \\
\hline Avó & & 3 & 37,5 \\
\hline Mãe & & 2 & 25 \\
\hline Irmã & & 2 & 25 \\
\hline Esposa & & 1 & 12,5 \\
\hline Total & & 8 & 100 \\
\hline
\end{tabular}

Fonte: Extraído do SPSS versão 24. OBS: SPA - Substância Psicoativa.

Os resultados provenientes da análise dos conteúdos discursivos possibilitaram a captação/percepção de situações cotidianas que transformam consideravelmente o ambiente familiar. A densidade e a complexidade de viver com um familiar adicto de SPAs, segundo as participantes, geram uma transformação da esfera cotidiana do lar, fazendo com que esse local de troca, aprendizado, ensino, intimidade, espaço social individual e coletivo com estreitamento de vínculos efetivos fosse negativamente transformado.

O lar passa a ter outra roupagem, um status negativo, que traz um clima de energia ruim, de opressão, solidão, assemelhando-se ao que se vive em um cativeiro. Percebe-se que o sentimento e as situações de tensão estão presentes o tempo todo no cotidiano dessas participantes e acontecem de formas diferentes, em relação ao adicto ou à área denominada "lar, doce lar".

Tem-se a percepção de que esses familiares são aprisionados física e psiquicamente em seus lares, pois se pode observar em suas falas que, em alguns casos, o lar assume um papel parecido com o de um "campo de concentração ou de guerra”, em que as participantes estão o tempo todo em alerta, prontas para o que possa acontecer. Esperam sempre o pior e, envolvidas pela tensão, dão lugar ao medo; em casa, passam a refletir sobre a situação e, em decorrência do peso de vivê-la, tornam-se aprisionadas pelos sentimentos em seus lares. 
“Eu tenho vontade de sair, não consigo sair. Não consigo sair de casa. Parece que estou amarrada, sabe! Com as pernas amarradas, não consigo andar. [...] Não tenho coragem (Olhos lacrimejam). Agora, eu não! Eu não saio de casa ... eu não saio de casa, acho que é pior, né! - Às vezes, eu deito e fico pensando, sabe! Que o maior arrependimento meu foi ter pegado ele pra criar” (Dona Nenê).

“E, quando comecei a pensar nisso, foi quando eu comecei a me recolher. Eu trabalhava à noite, na época, numa lanchonete, e eu ficava o dia inteiro dentro de casa de tanta vergonha, os meus filhos os maiores levavam os menores para o colégio e eu ficava em casa [...] eu passei durante muito tempo dentro de casa a ponto de não sair no quintal; eu levantava, os meninos já eram responsáveis por arrumar a casa, fazer alguma coisa, e eu levantava, arrumava as meninas [...]" (Bebel).

O familiar do dependente de SPAs é rotineiramente colocado sobre extremo estresse biopsicossocial, que, de forma direta, interfere na dinâmica da família e do lar. Os indivíduos sob estresse passam a apresentar sintomas físicos, como dores no corpo em geral, cansaço, desânimo, entre outros (Sales et al., 2019).

Os sintomas que comprometem a função psíquica abrangem alterações de humor, inabilidade de resposta a determinadas situações. Estão presentes sintomas que vão desde uma euforia intensa até um período de forte e progressiva tristeza, dificuldade de compreensão, hipervigilância a todo tempo. A sintomatologia de desarmonia social aparece sobre a forma de isolamento social, reclusão do indivíduo, que deseja ficar sozinho e recusa convites para estar no meio de outras pessoas, e dificuldade de relacionamento interpessoal (Carvalho, Nantes, \& Costa, 2020).

De acordo com a Constituição Federal, “a casa é o asilo inviolável do indivíduo, ninguém nela podendo penetrar sem o consentimento do morador" (Brasil, 1988), o que remete à ideia de local seguro, aconchegante, de descanso, paz e harmonia, o refúgio de cada ser. A presença da drogadição ocasiona uma disruptura no conceito de lar, ocorre uma desestruturação uma vez que o familiar codependente passa a vivenciar situações nesse ambiente.

De forma crescente e muito perceptível, a essência e a energia desse ambiente vão assumindo outras características, e, para os familiares, quando caem em si, é como se estivessem vivendo em uma prisão. Ocorre por diversos momentos uma inquietação e insatisfação de estar em um ambiente carregado de conflitos e situações que geram um sentimento de impotência em relação à drogadição (Costa, 2017; Carvalho, Nantes, \& Costa, 2020).

A mudança de paradigma e a visão sobre o lar como algo negativo e opressor advêm do processo que o codependente vivencia desde o momento em que soube da presença das drogas no meio familiar, até que ele chegue ao nível máximo de exaustão emocional. Nessa fase, a crise identitária, os pensamentos reflexivos e o estranhamento com tudo e com todos são muito comuns. O codependente se sente sem saída naquela situação vivida, não sabe a quem recorrer, está impotente e inerte às situações vindouras e, além do mais, tem que lidar com situações cotidianas. As pessoas que não vivenciam essa experiência de morar com um adicto podem considerar que essa situação seja fácil e aparentemente sem tanta importância, mas, para os codependentes, é um fator a mais de adoecimento, mais do que isso, uma sobrecarga (Carvalho, Nantes, \& Costa, 2020).

As participantes apontam em suas falas uma demanda domiciliar que lhes gera uma sobrecarga e que corrobora para seu adoecimento, e elas, cada vez mais, inclinam-se a não se afastarem do lar pela responsabilidade e pelo dever do fazer doméstico. Elas apresentaram indícios de estar além da fase de exaustão emocional, sendo essa carga considerada, ainda que inconscientemente, um fardo.

Foi possível perceber nas falas das participantes que, pelo fato de serem mulheres, pesa sobre seus ombros o dever de cuidar do lar e de seus familiares, o que significa que, além de terem que lidar com inúmeras situações estressantes e por vezes assumir a direção do lar e estar na linha de frente do cuidado ao seu familiar adicto, ainda têm que se encarregar das atividades domésticas. Estas poderiam ser distribuídas entre os moradores da residência, para que essas mulheres pudessem cuidar um 
pouco de si. Foi possível perceber ainda que essa sobrecarga põe em risco outros tipos de vínculos, tornando-os mais frágeis, como se pode observar nos depoimentos a seguir.

"Eu tenho que arrumar janta, tenho duas marmitas para o meu filho e para o meu marido levar para o almoço, tem que fazer janta, limpar casa, lavar roupa, olhar menino" (Marilda).

"Só que ele não ajuda, ele não ajuda. Quando eu peço que é dar banho no meu marido ou tirar ele da cama e pôr na cama [...] aí eu tenho que dar almoço, de tarde eu tenho que trocar, à noite muitas vezes eu tenho que pelejar com ele sozinha para trocar ele para dormir, porque não tem ninguém para ajudar. Então, como que eи vou manter, cuidar dele sozinha, não tem como. [...] fiz uma inscrição para colocar ele no asilo, colocar no asilo, porque eu não posso, como eu vou cuidar dele sozinha, ninguém quer me ajudar. Então, eu acho que não é pecado!” (Lineu).

"Ah, porque peço ele para me ajudar a fazer as coisas, ele não ajuda! Sai... eu falo assim: 'Só por a roupa lá!' Porque a roupa dele a máquina lava sozinha ... e para pôr no varal sozinha, assim que eu falo com ele! 'Você tem que me ajudar, pra poder manter, né, as coisas" (Dona Nenê).

A responsabilidade pelos serviços domésticos é ainda em sua maioria uma forte atribuição das mulheres em decorrência da cultura e história social. A jornada tripla de trabalho imposta às mulheres é um fator inegável de sobrecarga e adoecimento, pois, no transcorrer do tempo, um processo de mudança caminha lentamente e se supera a cada dia, contra um paradigma fortemente estabelecido na sociedade que é o patriarcalismo (Costa, 2018).

Com o processo de avanço tecnológico, globalização e industrialização, a mulher foi se inserindo no ambiente de trabalho, conquistando seus direitos por meio de muita luta. Porém ainda tem que lidar com situações desfavorecidas em relação à divisão sexual do trabalho, como salários inferiores aos dos homens, assédio moral e sexual por ocupar cargos que pelo senso comum seriam de homens, a exigência de qualificação para se destacar em meio aos concorrentes do sexo masculino, e, quando grávidas ou quando têm essa pretensão, são colocadas em situações de discriminação e até ameaçadas de desligamento do trabalho. Isso quando a mulher já está inserida no mercado, caso contrário, nem consegue o emprego (Tavares \& Barbosa, 2015; Costa, 2018).

$\mathrm{Na}$ tríade profissional, familiar e educacional, que forma a tripla jornada de trabalho, a responsabilidade familiar, que abarca todas as situações rotineiras de uma casa, é a maior sobrecarga e desafio para as mulheres, pois, no campo profissional e educacional, as mulheres, com muita insistência e resistência, têm ocupado seu espaço, mesmo que muito distante da representação masculina (Pereira \& Lima, 2017).

A esfera do lar traz às mulheres um papel social que é um desafio a ser superado, pois a responsabilidade com serviços domésticos, educação dos filhos e manutenção da família em geral pesa fortemente sobre os ombros das mulheres. Isso configura a responsabilidade por entregar cidadãos "normais" e produtivos à sociedade, o que é, sobretudo, uma forma de controle sobre o corpo feminino (Tavares \& Barbosa, 2015; Costa, 2018).

Com a presença das drogas no seio familiar, o desafio de cuidar da família, papel atribuído às mulheres pela cultura machista, torna-se mais complexo, porque um de seus membros foge às normas sociais e fica reservada a elas a responsabilidade de "realinhamento" desse indivíduo. Nesse caso, as mulheres tornam-se ainda mais "reféns". A maioria assume o papel de "Chefe" da família e cai no seguinte paradigma: trabalhar, estudar para se capacitar, cuidar do lar e ser a provedora de tudo e de todos, mas o conviver com um adicto requer um "cuidado/vigilância" 24 horas por dia. Isso torna essa jornada ainda mais árdua e pesada e contribui fortemente para o adoecimento psíquico, físico e social dessas mulheres, sempre expostas à extrema tensão (Costa, 2018; Rodrigues, Sanches, Oliveira, Pinho \& Radovanovic, 2018). 
Outro momento em que a tensão fica mais evidente na fala das participantes é durante a noite. Relatam ter insônia, além de passar por situações geradoras de estresse, insegurança e medo. Isso corrobora ainda mais para o adoecimento físico e psíquico dessas mulheres, pois têm o seu sono e o seu momento de descanso prejudicados.

Foi possível notar no discurso das participantes que elas são consumidas e têm toda a sua energia sugada pela forte preocupação com o adicto, quando ele está fora de casa, em relação ao que pode acontecer com ele ou à condição em que voltará para casa:

"Preocupada com o menino na rua. O portão com cadeado, só encostado, a porta aberta, dá para dormir?! (Faz sinal de indagação com os braços). Quando você sabe que está dentro de casa, deita e dorme um sono tranquilo. Deito, levanto, olho na janela. Se ele vem, se ele está por ali. Igual essa noite, essa noite eu levantei era 1 e pouca, depois passou, eu fiquei acordada. Ai, parecia que eu estava escutando conversa dele" (Dona Nenê).

"Eu não dormia porque eu não sabia onde ele estava. Eu não sabia o que estava acontecendo, eu não sabia o que podia acontecer, então eu não dormia. [...] E era como se a noite não passasse e às vezes eu ficava, pegava o telefone, olhava a hora, eu esperava o telefone tocar e ele não fazia contato nenhum comigo, e eu esperava a hora passar e a noite não passava, eu esperava o dia clarear para eu poder ligar para o trabalho dele para saber se tinha acontecido alguma coisa e aquilo não passava, eram noites intermináveis” (Bebel).

"Quando ele sai, a gente fica naquela expectativa de como vai chegar. Como que vai chegar aqui em casa hoje? A gente tem medo de um carro atropelar ele" (Florianinho Carrara).

"Acho que ela vem da ansiedade das preocupações, porque parece que à noite ele bate muito, sabe! Aì, de noite, eu acordo e fico assim: "Mas por que que isso está acontecendo? Por que o meu filho não conversa comigo? Ele me tratava tão bem, com carinho. Por que tá acontecendo isso e isso na minha família, você entendeu? "(Dona Abgail).

A ansiedade, associada com a preocupação, gera nos familiares um sentimento potencializado de hipervigilância e extrema tensão, uma vez que ficam muito ansiosos por não saberem onde o familiar adicto está, muito menos o que está fazendo. Tal instabilidade emocional faz com que os codependentes entrem em um estado de alerta máximo por não saberem o que está por vir e, devido a experiências anteriores e na leitura do "repertório", esperam sempre o pior. Esse comportamento de hipervigilância é bastante danoso para a saúde física e psíquica dos indivíduos dos familiares por não permitir que tenham sequer um momento de relaxamento ou descanso, colaborando para o aparecimento de doenças de cunho biológico ou mental (Melo \& Cavalcante, 2019).

Beattie (2017) salienta que os comportamentos codependentes são bastante destrutivos, ao ponto de impedirem que o codependente encontre equilíbrio, satisfação e paz. Entre os comportamentos que permeiam os indivíduos acometidos por essa patologia emocional cabe destaque para: diligência, baixa autoestima, repressão, obsessão, controle, negação, falta de comunicação, dependência, insegurança, sentimentos emotivos fragilizados, raiva e até mesmo disfunção sexual. Os comportamentos de obsessão e controle estão intimamente ligados ao quadro de hipervigilância e extrema tensão, que desencadeia uma série de reações negativas e orgânicas nos indivíduos codependentes.

Quando o adicto está em casa, a preocupação dos codependentes se prende ao cuidado com a própria vida ou do adicto em razão de outras comorbidades, além de o mesmo apresentar comportamentos que importunam a paz de seus familiares. São essas situações que mantêm os familiares a todo momento como reféns e por isso sofrem antecipadamente, 
pensando que algo ruim pode acontecer e que não poderão fazer nada para salvar o adicto. A seguir, apresentam-se algumas falas que ilustram bem esses momentos, e a participante aqui denominada Lineu é a que relata momentos de maior medo:

“Esse meu neto que é dependente químico, (continua) 'porque o negócio é o seguinte, se você não dormir, eu também não durmo'. Porque ele bate com a vasilha, ele grita, ele bate nas coisas, ele vai para o quarto e faz batuque, sabe o que é batuque? Ele pega um pau ou mão, sei lá e começa a bater nas mesas (faz sinal de batuque com as mãos), na mesa de computador, ele fica no computador a noite inteira. [...] Sempre atenta, estou sempre atenta! Então, escuto, vou na porta do quarto dele. [...] Mas, quando ele bebe! Meu Deus! Nosso Deus! (Face aterrorizada) é muito triste, é muito triste. Tem! Tem nesse ponto dele, quando ele bebe, a pessoa não pode ... deu não poder dormir direito, com medo dele aprontar alguma coisa pior dentro de casa, entendeu! Se ele arranca um fio de luz, o que mais esse menino pode fazer? É ele entrar dentro de casa ... aí eu já fico ... entendeu! Já fico ali ô, pensando o que ele pode fazer, se ele vai dormir ou se ele vai começar a bater com as coisas, se ele não vai estragar uma televisão. É isso que eu penso, é isso que eu fico preocupada, na minha casa, é isso. A gente não tem sossego, entendeu?" (Lineu).

“Agonia, medo, medo de dá um problema nele lá dentro do quarto e a gente não vê, né. E, no dia seguinte, a gente encontrar ele morto. [Voz de choro] E, se eu tiver lá à noite, igual essa noite eu dormi lá, se a pessoa passar mal, eu não sei mexer naquele aparelho, não sei medir esse negócio de glicose. [...] A minha mãe tem medo é disso. Da gente achar ele morto lá dentro do quarto" (Florianinho Carrara).

As substâncias psicoativas são capazes de provocar nos indivíduos disfunções psíquicas que fazem com que tenham comportamentos agressivos, inoportunos e que podem levar até mesmo à violência física e verbal. Nesse contexto, as pessoas que mais sofrem com esse risco iminente de violência são os familiares dos adictos, por estarem mais próximos e compartilharem a mesma casa. Com isso, passam a vivenciar outros tipos de situações em que o sentimento de medo aparece sobre uma nova ótica, o medo de seu próprio ente querido (Rodrigues et al., 2018).

Costa, Oliveira, Rodrigues \& Ferreira (2015) salientam que a violência é um fenômeno que se caracteriza por atos que geram danos psicológicos, físicos, morais e verbais, praticados por um indivíduo único ou um grupo contra outra pessoa. Já a violência doméstica é entendida quando esse fenômeno ocorre dentro do lar, entre indivíduos que partilham de intimidade entre si e residem na mesma casa. A violência é entendida como um grave problema de saúde pública e social, que necessita da intervenção de aparatos do Estado, haja vista o dano irreparável na vítima que sofre com a violência, que, quando não tem sua vida ceifada, fica com traumas decorrentes das situações vividas de medo e tensão.

De outro modo, Beattie (2017) aponta o medo desenvolvido pelo comportamento codependente, que leva a uma preocupação excessiva, obcecada e controladora direcionada ao adicto. Como estão em constante "processo de salvar" seu familiar, o medo de perdê-lo para a droga ou comorbidades causadas por ela gera nos familiares um sentimento de ansiedade, previsão de pensamentos negativos e espera de que aconteça o pior, assim como ocorre nos casos de violência iminente a que estão expostos.

No que tange ao risco de violência, foi possível perceber que o convívio com um familiar dependente de SPAs, na maioria das vezes, tem ligação com o tráfico de drogas, que implica para os familiares riscos iminentes de vida, uma vez que sofrem ameaças, são coagidos e temem por sua própria vida. Tais situações foram enredadas pelo familiar adicto, como mostra a fala de Bebel, que demonstra profunda arrelia ao ter sua família e seus filhos expostos ao perigo, devido ao envolvimento de seu familiar com uma parente de um traficante: 
"Então, para mim, ali foi um requinte de crueldade muito grande que você comprometer uma família, você comprometer uma criança, por conta de uma demanda que é sua, é muito pesado. [...] minha mãe disse: 'Junta as crianças e vamos embora!' [...] as crianças já estavam de pijamas, prontas para dormir, a caminha deles já estava arrumada, já estava tudo direitinho, nós fechamos a casa e saímos, deu tempo só de pegar as crianças. [...] Cadê ele? Porque o meu sobrinho vai subir aqui até 5 horas da tarde, se ele não pagar, meu sobrinho vai vir aqui e vai ser pior, ele vai subir de 'cavalo' e vai pegar todo mundo, eu olhei pra ela, disse: 'Está bom!'” (Bebel).

Também a participante Tuco relata em seu discurso momentos vividos com seu familiar. Declara que, durante situações que geram tensão, não sabe o que deve fazer e relatou ainda uma atitude extremada de trancá-lo no quarto e, em outro momento, vivenciou dentro de casa a crise de abstinência e também precisou se arriscar, expondo-se com terceiros para manter a ordem em sua casa:

"Eu não tinha mais como consolar, eu esperei, tranquei ele dentro do quarto até ele melhorar. Falei que, se ele saísse de lá, eu ia chamar a polícia para ele [...]. A minha casa, o quarto da minha mãe e minha irmã embaixo, a minha casa é muito grande, e eu e ele em cima, às vezes 2 ou 3 horas da manhã, ele batia, eu já passei noites com ele dando crise de abstinência, aquilo ele tremendo. [...] ai eu comecei a ver de noite chegar motoboy pra entregar CD, pra entregar não sei o que, eu disse: 'Para!' Aí um dia eu desci e mandei o motoboy voltar e disse: 'Ou você sai daqui ou eu chamo a polícia!'. Ai depois ele veio brigar comigo" (Tuco).

De acordo com Domingues, Desses \& Queiroz (2015), estima-se que, em torno de 44\% dos homicídios no Brasil, na faixa etária de 12 a 18 anos, são decorrentes da ligação com o narcotráfico, que, por meio de suas próprias "regras" e "leis", executa suas cobranças de forma violenta, subjugando o adicto devedor e sua família a situações de extremo perigo, que, em casos mais fúteis ou graves, culmina no ato de homicídio do próprio adicto ou de algum membro familiar por vingança.

O risco iminente de vida da família do adicto é uma situação bastante grave, pois ele compromete a segurança de toda a família e poderá colaborar também para o aumento da violência e rixa entre famílias distintas do mesmo território ou localidade próxima, uma vez que a ameaça de vida, fisiológica e instintivamente, desencadeia no ser humano duas respostas: luta ou fuga. Com isso, a situação tende a piorar e tomar proporções muito maiores, fazendo com que os familiares fiquem cada vez mais adoecidos por esse cotidiano incerto e perigoso (Soccol, Terra, Ribeiro, Teixeira, Siqueira \& Mostardeiro, 2014; Domingues et al., 2015).

Beattie (2017) salienta que, em situações de extremo estresse, o familiar codependente, diante de alguma situação de perigo iminente ou nível máximo de preocupação, obsessão e controle, pode se comportar de maneira agressiva, coercitiva e até mesmo ter ações equivocadas e precipitadas na tentativa de afastar o adicto das drogas. Sente-se impotente com as palavras e, nessa fase de controle, pode haver uso de força física ou atos de aprisionamento do adicto, o que, por fim, fragilizará ainda mais a relação entre família e adicto, bem como as relações sociais e interpessoais do familiar codependente.

Diante desse cenário, é possível notar nas falas das participantes que essas situações trazem uma enorme instabilidade para os familiares, e os conflitos crescentes e intermináveis caminham para um estranhamento no lar, uma esfera com uma energia diferente daquele arquétipo de lar que as pessoas idealizam ou vivem quando não são acometidas por uma doença devastadora como as drogas. Buscam, quando conseguem e têm forças, espaços e locais extralar, ares, climas e energias diferentes daquela tão pesada e tóxica de suas casas, causadora de opressão.

Dá para perceber que buscam no seu pequeno ciclo social pessoas com quem possam dividir o fardo, mesmo que por meio do diálogo, pois se sentem tão aprisionadas que o simples fato de falar sobre aquilo traz um pouco de alívio, é como 
escape de outras práticas danosas à própria saúde, como evitar do hábito de fumar. As falas de Bebel, Marilda e Dona Nenê espelham isso.

"A casa tinha uma energia muito pesada, os meus filhos eram muito tristes, eu creio que eles eram iguais a mim, sobressaltados, agitados; eles viviam em alerta, porque, a qualquer momento, alguma coisa poderia acontecer. Então, eles viviam ali em alerta, eles não eram crianças normais, eles eram crianças atentas, crianças espertas que estavam prontas para tudo. [...] por estar muito entregue, estar muito rendida e envolvida nessa situação, eu não conseguia levantar da minha cama. Eu ficava o dia inteiro, ali foi o pior momento, porque tinha uma pressão do ambiente" (Bebel).

"Tem dia que eu fico bem, tem dia que eu não fico. Essas voltas que eu dou assim, dou as voltas para não ficar parada, entendeu? Ah! Muito difícil (Franzindo o rosto). [...] eu fumo de nervosa, agitação. Para você ver, hoje eu estava andando lá para não fumar (aponta para rua). Porque, se eu ficar parada dentro de casa, eu fumo um maço por dia. Aí, eu saio para rua, aí eu não fumo” (Marilda).

“Às vezes, eu vou, assim, fui no Manoel Honório, outro dia que tem uma irmã que mora lá. Aí, comecei a chorar, aí, comentei para ela as coisas dele (aponta para o quarto). Ai, ela pegou e falou assim: 'Não fica assim não!' Eu falei: 'Irmã, eu não quero dividir meus problemas com ninguém, não quero mesmo. Mas, infelizmente eu vou conversar com você,", (Dona Nenê).

São múltiplos os fatores que podem colaborar para o início de um quadro de melancolia e depressão. No caso do cotidiano vivido com o adicto, devido ao isolamento social ao qual os familiares são alocados por constrangimento, medo e impotência, o diálogo como forma de expressão, liberdade e compartilhamento fica comprometido, principalmente pelo sentimento de vergonha. O codependente passa a não externar suas inquietações e embute dentro de si essa "luta" diária. A comunicação verbal e a não verbal são a forma mais expressiva de troca e aprendizagem entre os indivíduos, reforçam os laços interpessoais e amenizam o sentimento de aflição, pois, sem comunicação, não há interação (Beattie, 2017; Gonçalves et al., 2018).

Com relação a várias situações que permeiam o cotidiano dessas pessoas, quando ocorre o comprometimento da comunicação decorrente de alguma situação externa, é um indicativo de que algo não vai bem e de que o sujeito está com outras dimensões abaladas. Tal situação colabora para um quadro de desequilíbrio emocional, causando desordem de sentimento e consequentemente oscilação de humor no indivíduo. Experienciar essa desordem emocional gera nas pessoas estranhamento de si e de tudo ao seu redor e, gradativamente, vão tendo sentimentos de ansiedade, tristeza, crise de identidade e apatia emocional muito potencializados (Gonçalves et al., 2018).

O quadro de depressão e melancolia está na maioria dos casos associado com a dependência de nicotina, utilizada inconscientemente como uma "ferramenta" para amenizar a ansiedade e a ociosidade. Como mencionado anteriormente, o quadro de alteração que afeta o humor, tal como o início da depressão, impacta negativamente a forma como os indivíduos enxergam suas vidas e o local no qual estão inseridos. Com isso o estranhamento do lar, o desconforto no mesmo e o desejo de fuga são tentativas dos indivíduos de associaram isso com o externo, quando, na realidade, a questão é interna (Gonçalves et al., 2018).

Foi possível perceber nas falas das participantes, em específico na de Bebel (mais frágil por estar grávida na época), que todas essas tensões fazem com que não vejam possibilidade em outros ambientes, demonstram tamanho cansaço, que é 
como se a cada minuto fossem desfalecendo e se enfraquecendo dentro de seus lares, tomadas por medo, impotência, dificuldades diversas. Relatam ainda a sensação de estarem sendo vigiadas:

“[...] eu não conseguia chegar na porta, porque, a qualquer momento, eu me sentia vigiada, não chegava na porta e tinha um cuidado muito grade com os meus filhos, porque eles tinham a necessidade de ir para o colégio, de voltar, de às vezes fazer alguma coisa, mas eu não podia tirar isso deles. [...] mas eu tinha muito medo, constantemente eu tinha medo. Às vezes, estava em casa e me vinha na cabeça aquela coisa, a imagem do homem montando no cavalo com uma arma apontada, passando e atirando, e acontecendo alguma coisa, isso foi durante muito tempo. E passar por uma gravidez sentindo esse medo foi uma coisa terrível, foi uma coisa complicada, foi uma coisa que me desestruturou muito [...]" (Bebel)

Conviver com um familiar adicto é estar constantemente sob ameaça, extrema tensão, medo e insegurança. Tais situações potencializam ainda mais o quadro de comprometimento neurológico e pensamentos negativos. Sentir-se vigiado em decorrência da ligação com um familiar adoecido pela droga é um sentimento doloroso e comum, haja vista que os familiares deste vivem em constante alerta, esperando sempre o pior. Essa situação implica diretamente a dinâmica de toda a família, que passa a assumir comportamentos e atitudes preventivas para minimizar qualquer situação de conflito ou perigo (Reis \& Oliveira, 2015).

A gravidez gerou em Bebel um abalo emocional ainda maior, o que não é esperado, uma vez que a gravidez é, na maioria dos casos, desejada pela mulher e configura-se como um momento especial e único para ela, pois passa por mudanças físicas e orgânicas, como também alterações psicológicas.

Comumente, para a mulher, esse é o "milagre da vida", ela, como um ser capaz de gerar outra vida, pode vivenciar esse momento de múltiplas formas, por ser também algo que envolve a subjetividade de cada uma. A gravidez propicia à mulher a vivência de uma mescla de sentimentos positivos, como felicidade, amor, alegria, satisfação, aceitação, ressignificação da vida, revisão de prioridades e sonhos, e planos diante dessa realidade. Porém a presença de sentimentos desagradáveis também pode existir, entre eles medo, insegurança, dúvida, ansiedade, estranhamento, pensamentos complexos da responsabilidade de cuidar de outra vida, assim como de educar uma criança e torná-la uma cidadã. Ou seja, é um momento que tem grande impacto na vida da mulher (Azevedo, Hirdes \& Vivian, 2020).

O processo gravídico, afetado por questões da adicção, seja pelo próprio uso, seja de um familiar próximo, será um enorme complicador no sentido físico e psíquico para essa mulher, que, além de ter que lidar com suas próprias subjetividades, será obrigada e exposta a lidar com todas as mazelas que a dependência de SPAs traz para a vida dos sujeitos e de seus familiares. Essa situação fará com que a mulher vivencie outros sentimentos, além daqueles intrínsecos à gravidez, sendo uma experiência negativa, traumática e que gera danos irreparáveis à saúde tanto física como psíquica, pois essa mulher pode desenvolver processos negativos internamente e potencializados. Isso pode culminar em uma disfunção psíquica como um quadro de depressão, ou alterações físicas e metabólicas em que a mulher não tenha condições de levar a gravidez até o final (Oliveira, Viegas, Santos, Silveira \& Elias, 2015; Ramalho, Ferreira, Lima, Ferreira, Souto \& Maciel, 2017).

Cabe mencionar que foi possível ainda perceber por meio das falas das participantes estratégias criadas pelos familiares codependentes, em uma tentativa de escape do lar, como o revezamento de pessoas para dividirem a responsabilidade de cuidar do adicto. Pôde-se observar que a "prisão domiciliar" não acontecesse apenas fisicamente, mas psiquicamente também.

É perceptível que esses familiares em estado de codependência têm uma transferência emocional com seu familiar, que as "amarras" que os prendem se fazem presentes mesmo quando estão em um local desejado por muitos para diversão e a 
quilômetros de distância do adicto. Essa "amarra" colabora para um isolamento social, bem como para a mortificação de toda a família, como bem relatado a seguir:

Isso tudo preocupa a gente, né. Tira o prazer da gente de viver, de viver uma vida plena de você ter um prazer para falar assim: 'Hoje eu vou tomar um banho, vou sair, vou levar minha mãe para passear'. A gente não sabe como a pessoa vai chegar. Muitas vezes, a gente deixa de sair por causa dele. Então lá em casa, na minha família, a gente não tem prazer mais nem para sair de casa. A nossa vida fico resumida somente nesse mundinho. Só no mundinho familiar mesmo, mesmo para ir numa igreja aos domingos. Ou vai duas e ficam duas. A mãe fica, eu vou sozinha com uma irmã minha. Sempre tem que ter alguém com a mãe, porque não pode deixar ela sozinha com ele. Tem dia que a gente quer sair, igual ontem, teve aniversário de uma amiga minha ali, a gente nem foi. Medo de sair, né. Mas eu fico com pena da minha mãe, porque às vezes ela quer sair e ele pode deixar um gás ligado. Igual um dia ele deixou ligado (fala chorando). Se minha irmã que mora em cima não sentisse o cheiro, ia pegar fogo lá na cozinha. [...] É nessa parte que a gente fica muito chateada. [...] Aí, a gente estava lá, que que aconteceu? A minha mãe com pensamento nele aqui 24 horas. Ela tirou o prazer nosso todinho lá. Nós não tivemos prazer lá, nem de aproveitar muito, porque o pensamento dela estava aqui e ela ficou só deitada. Tinha piscina grande toda vida, tinha piscina, churrasco todo dia, comida variada e minha mãe só deitada, né. Porque ela também estava com depressão, tinha acabado de sair de depressão. Ela ficou deitada lá os quatros dias. A gente saiu para divertir, chegou lá, uma tristeza danada também. Fica uma família de pessoas caladas, a gente se isola, porque... não é porque a gente queira, mas como a gente vai fazer? Não pode ir para lugar nenhum. Porque, se vai, a gente tem medo dele fazer alguma coisa aí. Ela já tem medo até de sair de casa, sempre uma fica com ela” (Florianinho Carrara).

Os sentimentos de preocupação, tristeza e vergonha que permeiam o cotidiano do familiar que convive com um adicto de drogas, associado com o quadro de codependência, levarão gradativamente a família a não interação social. Isolamento social é quando um indivíduo ou grupo se apartam voluntariamente ou não de suas relações sociais, trocas e compartilhamento com os outros membros da sociedade. Inúmeros fatores podem contribuir para o isolamento social, internos ou externos ao ser humano. As pessoas acometidas pelo isolamento sofrem a dificuldade de se relacionar com outros seres humanos, deixando de participar de e se envolver com várias ações de cunho social, além de comprometer o psicológico desses indivíduos (Soccol et al., 2014).

O isolamento social é caracterizado como um dos primeiros sintomas para o aparecimento da depressão. Assim é considerado, pois o indivíduo que não interage com outros membros da sociedade fica limitado, não cresce e nem se aprimora como ser humano. Viver em sociedade é viver em rede, constante troca e aprendizado, compartilhamento de fenômenos internos e respeito mútuo. O isolamento pode acontecer por alterações funcionais e psíquicas congênitas do indivíduo, ou quando o mesmo sofre com alguma situação externa, que lhe gera profundo abalo mental e social, como é o caso da adicção, que impacta negativamente o indivíduo de todas as formas possíveis. Causa uma desestrutura multidimensional: física, psíquica, biológica, social e espiritual em que o indivíduo se desequilibra e tenta formas e estratégias para se realinhar, encontrando enorme dificuldade por estar com todas as suas bases fragilizadas, inclusive seu lar (Alvarez et al., 2014).

Em se tratando do lar, doce lar, como prisão domiciliar, o desejo das participantes se soma ao da Dona Abgail, que não suporta mais esse problema e o peso do cotidiano de toda a família, como expressa em sua fala:

"Porque eu acho que eu, indo embora, eu saio do problema, sabe! Eu vou até levar ele, porque eu vou pensar sempre nele, mas aí eu não vou saber de dia a dia de todos, né!” (Dona Abgail). 
A dor é um sentimento subjetivo, experienciado por cada pessoa de maneira diferente, é uma sensação que gera desconforto e mal-estar em quem a sente. Esse sentimento pode estar ligado a estímulos externos, causadores de dor na dimensão biológica, como pode acometer a dimensão psicológica e gerar uma sensação ainda mais subjetiva, que perpassa os limites humanos e gera nos indivíduos um grande impacto emocional. Diferente da dor física, que possui terapias medicamentosas que cessam ou amenizam esse sentimento, a dor psicológica fragiliza o emocional e promove rupturas mentais nos indivíduos. Essa disfunção psíquica deixa os indivíduos tão desnorteados e sem ação que paralisa e torna impotentes os sujeitos, de forma que estes começam a ter dificuldades de dar seguimento saudável a suas vidas, que perdem qualidade (Baptista \& Melancolia, 2011).

A dor que afeta a estrutura psicológica no que tange ao subjetivo é tão incômoda e causadora de sofrimento que os indivíduos tentam criar e planejar formas de se livrarem desse sentimento que os consome gradativamente, visualizando a fuga como "escape" do problema. Nessa fase, os indivíduos já estão em um nível de exaustão emocional muito avançado, no qual não encontram mais forças para lutar e passam a recuar e a fugir do problema como estratégia de se apartar da dor que se enraizou emocionalmente. Assim, o quadro de depressão já está instalado, os indivíduos não se reconhecem mais, agem de forma disfuncional, apresentam estranhamento com o meio social e seu lar, não sendo este mais um abrigo, mas sim um campo de concentração (Beattie, 2017).

\section{Considerações Finais}

Ao refletir sobre o ambiente domiciliar de codependentes como um ambiente de convivência com adictos de SPA numa perspectiva fenomenológica, compreendeu-se que esse "lar" pode se tornar uma verdadeira "Prisão domiciliar" quando a realidade cotidiana for marcada pelos múltiplos papéis ocupados pelas participantes, os quais são gerenciados juntamente com o cuidado ao familiar dependente químico. Cabe destaque para o convívio diário com situações estressoras, dolorosas e que lhes geram sentimentos ruins, como medo, insegurança, tristeza, além de conflitos familiares etc. Estes devem ser alvo do cuidado da enfermagem e da saúde de modo que o codependente seja visto e tratado como outra pessoa "doente em potencial", que também requer cuidados.

A limitação desta investigação se prende ao reduzido número de participantes, porém cabe mencionar que foi abordada a totalidade de potenciais participantes, conforme cadastro prévio fornecido pela UBS cenário de investigação, além da adoção da estratégia de confirmação da saturação teórica dos dados para reduzir tal limitação.

A presente pesquisa trouxe como contribuição as discussões dos resultados apresentados que podem subsidiar reflexões sobre o planejamento do cuidado profissional, a partir da compreensão das necessidades de saúde identificadas entre as codependentes numa perspectiva compreensiva fenomenológica. São recomendações dos autores para trabalhos futuros a realização de novas investigações sobre a temática investigada numa perspectiva fenomenológica em diferentes contextos e níveis de atenção à saúde.

\section{Referências}

Alvarez, S. Q., Gomes, G. C., \& Xavier, D. M. (2014). Causas da Dependência Química e suas Consequências para o Usuário e a Família. Rev. enferm. UFPE On Line, 8(3), 8-641.

Arreguy-Sena, C., Marangon, A. M. G., Gomes, A. M. T., Melo, L. D. D., Martins, R., Fontes, F. L. D. S. (2020). Representações Sociais sobre Esquecimento e Depressão por Pessoas Idosas: Abordagem Processual. Enferm. foco (Brasília), 57-62. 
Azevedo, C. C. A., Hirdes, A., \& Vivian, A. G. (2020). Repercussões emocionais no contexto da gestação de alto risco. International Journal of Development Research, 10(09), 40216-40220.

Baptista, M. C. F., \& Melancolia. (2011). Depressão e a Dor de Existir. Rev. Hosp. Univer. Pedro Ernesto. 10(2):6-11.

Beattie, M. (2017). Codependência nunca mais. tradução Marília Braga. https://codependentes.files.wordpress.com/2016/03/co dependencia-nunca-mais.pdf.

Brasil. (2020). Juiz de Fora, Minas Gerais. Plano Diretor Participativo. Análise Física e Socioeconômica. Juiz de Fora, Minas Gerais.: http://www.planodiretorparticipativo.pjf.mg.gov.br/pddu/index.htm

Brasil, Ministério da Saúde - Política Nacional sobre Drogas - Decreto $n^{\circ}$ 9.761, 11 de abril de 2019. Brasília: Ministério da Saúde, 2019. http://www.planalto.gov.br/ccivil_03/_ato2019-2022/2019/decreto/D9761.htm.

Brasil. (1988). Constituição da República Federativa do Brasil. Brasília, DF: Senado Federal: Centro Gráfico, 1988,292 p.

Carvalho, R. C. N., Nantes, R. F. P., \& Costa, M. L. (2020). Estratégia familiar de cuidado em saúde mental. Brazilian Journal of Development, 6(7), 50256-50271.

Costa, F. A. (2018). Mulher, trabalho e família: os impactos do trabalho na subjetividade da mulher e em suas relações familiares. Pretextos-Revista da Graduação em Psicologia da PUC Minas, 3(6), 434-452.

Costa, E. F. (2017). Uma Introdução Psicanalistica sobre A adicção.Rev.PsicoLogia.PT. http://www.psicologia.pt/artigos/text os/A1106.pdf.

Costa, A. P. S., Oliveira, D. A., Rodrigues, M. P., \& Ferreira, M. A. F. (2015). Violência Doméstica e Abuso de Álcool e Drogas na Adolescência. Rev. Ciência Plural, 1(2), 48-56.

Domingues, D. F., Dessen, M. A., \& Queiroz, E. (2015). Luto e enfrentamento em famílias vitimadas por homicídio. Arquivos Brasileiros de Psicologia, 67(2): 61-74.

Gonçalves, A. M. C., Teixeira, M. T. B., Gama, J. R. A., Lopes, C. S., silva, G. A., Gamarra, C. J., et al. (2018). Prevalência de depressão e fatores associados em mulheres atendidas pela Estratégia de Saúde da Família. Rev. J Bras. Psiquiatr., 62 (2): 101 9.

Maffesoli, M. (2010). O Conhecimento comum: Introdução à sociologia compreensiva. Traduzido por Aluízio Ramos Trinta [Internet]. - Porto Alegre: Sulina. 295 p.

Meira, E. C., Souza, S. S., Silva, T. A., Costa, L. C., Oliveira Vieira, L., Galvão, G. A., et al. (2020). Mulheres codependentes em convivência com familiar alcoolista. Revista Enfermagem Atual In Derme, 94(32): 1-9.

Melo, C.F, \& Cavalcante, I. S. (2019). A Codependência em Familiares de Adictos. Rev Fund Care Online,11, 304-310.

Melo, L. D., da Silva Jeremias, J., Shubo, A. F. M. F., Taroco, F. E., Spindola, T., Gomes Filho, et al. (2020a). Tabagismo, Hipertensão Arterial Sistêmica e Pandemia da COVID-19: uma Análise Psicanalítica Freudiana. Research, Society and Development, 9(11), e57891110240-e57891110240.

Minayo, M. C. S. (2017). Amostragem e saturação em pesquisa qualitativa: consensos e controvérsias. Revista Pesquisa Qualitativa, 5(7):1-12.

Nistchke, R., Tholl, A. D., Potrich, T., Silva, K. M., Michelin, S. R., Laeureano, D. D. (2017). Contributions of Michel Maffesoli's Thinking to Research in Nursing and Health. Texto e Contexto em Enfermagem, 26(4), 1-12.

Oliveira, P. P., Viegas, S. M. F., Santos, W. J., Silveira, E. A. A., \& Elias, S. C. (2015). Mulheres Vítimas de Violência Doméstica: Uma Abordagem Fenomenológica. Texto Contexto Enferm, 24(1), 196-203.

Pereira, A. M. L., \& Lima, L. D. D. S. C. (2017). A Desvalorização da Mulher no Mercado de Trabalho. Revista Eletrônica Organizações e Sociedade, 6(5), 133-148.

Ramalho, N. M. G., Ferreira, J. D. L., Lima, C. L. J., Ferreira, T. M, C., SOUTO, S. L. U., \& Maciel, G. M. C. (2017). Violência Doméstica contra a Mulher Gestante. Rev enferm UFPE on line., 11(12), 4999-5008. 
Reis, L. M., \& Oliveira, M. L. L. (2015). Drogas e violência: percepção social em uma comunidade. Rev. Eletr. Enf. 17(3), 1-5.

Rodrigues, T. F. C. S., Sanches, R. C. N., Oliveira, M. L. F., Pinho, L. B., \& Radovanovic, C. A. T. (2018). Sentimentos de famílias na dependência de drogas: à luz da sociologia compreensiva. Rev. Bras. Enferm., 71(5), $2272-9$.

Sales, C. C. F., Silva, L. F. F., Reis, L. M., Decesaro, M. N., Marcon, S. S., Oliveira, M. L. F. (2019). Social Risk for The Family of Drug Users Hospitalized Due to Physical Injury. Revista de Pesquisa: Cuidado é Fundamental Online, 11(2), 510516.

Soccol, K. L. S., Terra, M. G., Ribeiro, D. B., Teixeira, J. K. S., Siqueira, D. F., \& Mostardeiro, S. C. T. (2014). O cotidiano das relações familiares com individuo dependente químico. Cogitare Enfermagem, 19, (1), 121-132.

Tavares, A. D., \& Barbosa, R. B. (2015). A Mulher e a Tripla Jornada de Trabalho: Como esta Mulher Vivencia as Atividades Profissional, Familiar e Doméstica? Psicologia em Foco, 5(1), 510-516. 